\title{
PRELIMINARY SPACE IMAGE LINEAMENT MAPS OF ALASKA by
}

Ernest H. Lathram and Robert G. H. Raynolds U. S. Geological Survey

Examination of Images from Nimbus, NOAA and Landsat satellites has revealed a series of lineaments in the earth's surface in Alaska $1000 \mathrm{~km}$ or more in length (fig. 1). These lineaments occur as alinements of surface geologic structures, 1Inear valleys or ridges, and linear changes in tonal contrast marking differences in soil type, soil moisture, or vegetation. The lineaments are believed to represent the surface traces of zones of weakness deep within the earth's crust along which vertical or horizontal adjustments to earth stresses persistently recurred since at least Precambrian time.

A consistent pattern In the lineaments can be discerned in Alaska (fig. 1D), and throughout the North American Cordillera (fig. 2). This pattern is believed to represent a mosaic of crustal blocks, whose differential movements have guided the tectonic development of the Cordiliera.

Areas in which mineral deposits are known to be concentrated are alined along many of the lineaments or occur at lineament intersections, suggesting that the zones of weakness reflected by the lineaments provided felicitous pathways for upward movement of mineralizing agents. Other lineaments bound areas of high mineral concentration suggesting that some crustal blocks have had a tectonic history more favorable for mineralization than others. These conclusions suggest that the study of space image lineaments can provide new and fruitful approaches to the search for concealed mineral deposits.

In Alaska, some lineaments coincide in part with active fault traces and some separate areas of significantly different structure and geologic history. However, the movements along the zones of weakness which these lineaments are believed to reflect have been too slow and spread over too many millions of years for the 1ineaments to be considered as marking zones of present earthquake hazard.

Detalled discussion of the lineaments, and of interpretations as to their meaning, are contained in: 1) a paper presented by Lathram and Raynolds at the First William T. Pecora Memorial Symposium, Sioux Falls, South Dakota, October 28-31, 1975, and 2) Lathram and Albert, 1976, Significance of space image 1inears in Alaska, in Hodgson, R.A., Gay, S.P., and Benjamins, J.Y., eds., Proceedings of the First International Conference on the New Basement Tectonics: Utah Geol. Assoc. Pub. 5, p. 11-26. 

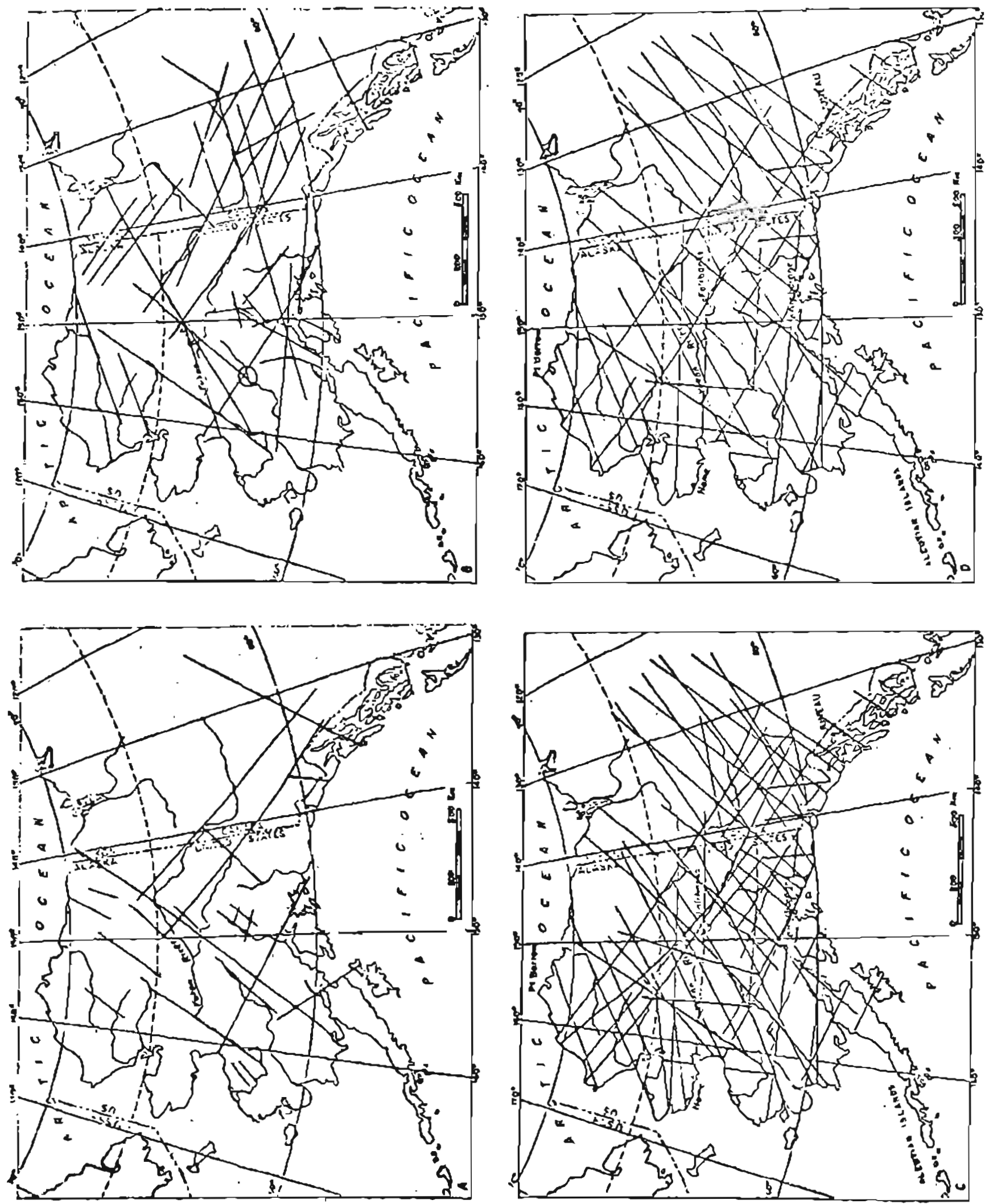

Figure 1. Space image lineaments in Alaska: A) Nimbus, B) NOAA, C) Landsat; D) Pattern formed by selected Landsat lineaments. 


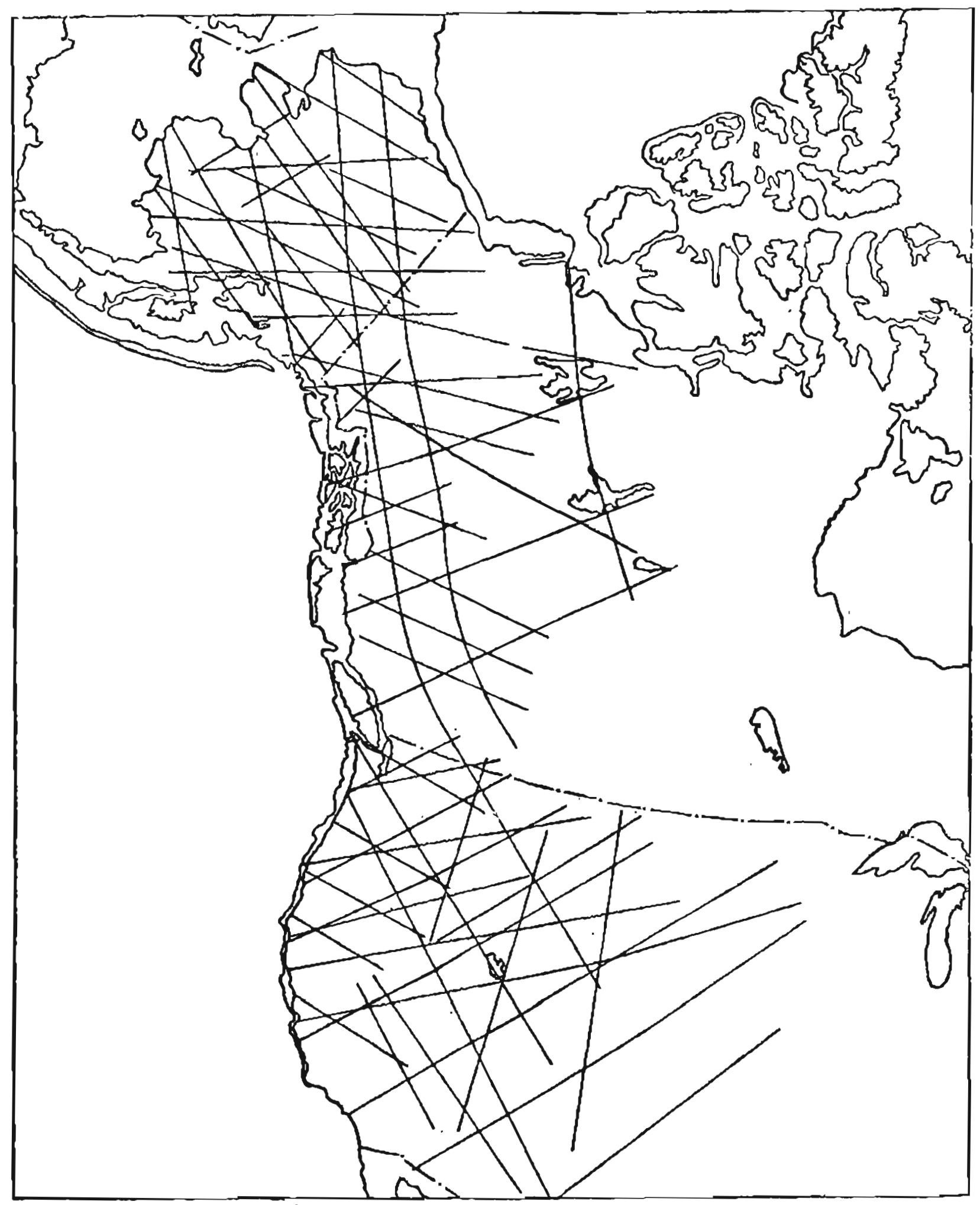

Figure 2. Space image lineament pattern in North American Cordillera. 